\title{
EPISTEMOLOGIA SOCIAL CONSTRUTIVISTA NO DIREITO: DESCENTRAMENTO EPISTEMO-LÓGICO DO SUJEITO (?)
}

\section{Jayme Camargo da Silva ${ }^{1}$}

Resumo: A hipótese da investigação é que a racionalidade pragmático-sistêmica no Direito manifesta uma espécie de descentramento epistemo-lógico do sujeito na fundamentação do conhecimento jurídico. Para demonstrá-la, analisar-se-á o seu modelo de conhecimento como uma instância da Epistemologia Social Construtivista. A autopoiesis será perquirida enquanto núcleo da comunicação pragmático-sistêmica. Especialmente, à luz da adaptação conceitual realizada por Luhmann na análise do Sistema Social. Por fim, comentaremos as reflexões de Teubner no ensaio "El Derecho como Sistema Autopoiético" (2005a); contemplando, assim, a origem da intuição intelectual desta investigação. As considerações finais provarão que a matriz pragmático-sistêmica no Direito confirma a hipótese delineada.

Palavras-chave: Epistemologia Jurídica; Matriz Pragmático-Sistêmica; Autopoiese; Descentramento do Sujeito; Construtivismo.

\section{SOCIAL CONSTRUCTIVIST EPISTEMOLOGY IN LAW: EPISTEMO-LOGICAL DECENTRING OF THE SUBJECT (?)}

Abstract: The research hypothesis is that pragmatic-systemic rationality in Law manifests a kind of epistemo-logical decentering of the subject in the grounding of legal knowledge. To demonstrate this, its model of knowledge will be analyzed as an instance of Social Constructivist Epistemology. Autopoiesis will be perused as the core of pragmatic-systemic communication. Especially, in the light of the conceptual adaptation made by Luhmann in the analysis of the Social System. Finally, we will comment on Teubner's reflections in the es say "El Derecho como Sistema Autopoiético" (2005a); thus contemplating the origin of the intellectual intuition of this investigation. The final considerations will prove that the pragmatic-systemic matrix in Law confirms the outlined hypothesis.

Keywords: Legal Epistemology; Pragmatic-Systemic Matrix; Autopoiesis; Decentering the Subject; Constructivism.

\section{INTRODUÇÃO}

"Todos os cretenses são mentirosos" Epiménides de Creta

1.1 Plano da Investigação

O presente artigo teve como embrião os seminários de doutorado em Direito da Unisinos ("Sistemas Sociais e Direito"), coordenados pelo professor Dr. Leonel Severo

$1 \quad$ Advogado licenciado na OAB/RS (65.719), Professor Universitário, Mestre em Filosofia pela Pontifícia Universidade Católica do Rio Grande do Sul (PUC/RS) e Doutorando em Direito na Universidade do Vale dos Sinos (UNISINOS), sendo bolsista CAPES-PROEX, Código de Financiamento 001. 
Rocha. As profícuas discussões em torno à Matriz Pragmático-Sistêmica no Direito abrangeram às obras do sociólogo alemão Niklas Luhmann (1983; 2002; 2016), bem como as do professor Gunther Teubner (1989; 2005a; 2005b; 2016). O nosso seminário remeteu ao capítulo de abertura da obra "El Derecho como Sistema Autopoiético de la Sociedad Global" (Teubner), intitulado "El Derecho como Sistema Autopoiético". Uma inquietante questão, todavia, veio à tona nos seminários e discussões que se sucederam: as reflexões dos autores citados dispõem ou não da categoria de "sujeito lógico" como pressuposto epistêmico de suas teses? Ou seja, o sujeito lógico do conhecimento, em ambiente pragmático-sistêmico, perde o status de verdade incontestável como condição de possibilidade do sentido, que Kant (2001) havia designado e Kelsen (1976), em certa medida, perseguido à ciência do Direito?

A questão que talvez seja simples para leitores qualificados conceitualmente ou "treinados" na teoria autopoiética, não emerge da mesma forma em leitores ávidos pela individualização do social. Claro está que no Brasil há um déficit filosófico notável na bagagem teórica de muitos juristas. Por vezes, a dificuldade é percebida até mesmo na Pósgraduação - lócus por excelência onde não se poderia manifestar esse gap teórico. Assim sendo, colocamos um ponto de interrogação entre parênteses ao final da segunda parte do título (que retrata a nossa hipótese), mirando contemplar aos diferentes níveis de compreensão dos leitores.

De fato, alguns colegas extravasam uma perturbadora dificuldade no processamento de dados, digamos assim, das teorias que não conservam o "sujeito" na base epistêmica. A dificuldade transforma-se em negação, às vezes, pelo tempo perdido com questionamentos errôneos; outros, inocentemente, perpetuam o equivocado humanismo da boa vizinhança. Questionam: não há sujeito na base cognitiva do sistema social? Indagação que é proveniente, em diversos casos, de colegas eivados de boas intenções, que aspiram contribuir para um "mundo melhor" através das teses que confeccionam. Não obstante, desconhecem os efeitos ambivalentes da ideia de "progresso", redundando na pressuposição da lógica (do desenvolvimento progressivo) que pretendem superar. Obstáculo que reaparece quando os sujeitos são equiparados a constructos ou artefatos semânticos do sistema social, nos aportes teóricos do professor Teubner.

Aliás, a justificativa científica da pesquisa respalda-se na superação dessas dificuldades, objetivando, portanto, refinar a compreensão dos juristas brasileiros acerca da 
Matriz Pragmático-Sistêmica no Direito. No que se refere à justificativa social, situa-se na condição da Epistemologia Social Construtivista de refletir o Direito conectado à sociedade de seu tempo (global e fragmentada). Aproximando-lhe, enfim, de sua função social, tendo em vista o resgate do compromisso democrático que o formalismo-normativista exilou da ciência do direito ao apartar-se da política.

Assim sendo, a hipótese da investigação é que a racionalidade pragmático-sistêmica no Direito manifesta uma espécie de descentramento epistemo-lógico do sujeito na fundamentação do conhecimento jurídico. Para demonstrá-la, analisaremos a construção do conhecimento pela matriz pragmático-sistêmica no Direito, que parece sugeri-la como uma instância da Epistemologia Social Construtivista. Então, examinaremos a autopoiesis com o intuito de identificar a articulação da comunicação e do sentido na racionalidade pragmáticosistêmica. Especialmente, à luz da adaptação conceitual realizada por Luhmann para a análise do Sistema Social. No tópico derradeiro, exploraremos as reflexões de Teubner no ensaio "E1 Derecho como Sistema Autopoiético" (2005a) (análise com unidade focal circunscrita ao antiindividualismo e ao antirrealismo epistêmicos, fundamentos da hipótese); contemplando, assim, a origem da intuição intelectual desta investigação. As considerações finais evidenciarão que a matriz pragmático-sistêmica no Direito não depende do sujeito lógico do conhecimento como condição do sentido.

Devemos advertir que a presente investigação configura-se como uma parte (revisada e atualizada, embora com identidades) de um estudo mais amplo, denominado: "Matriz pragmático-sistêmica e autopoiese: fundamentação do conhecimento jurídico fora da consciência do sujeito (?)". Portanto, este ensaio deve ser reparado sob o horizonte do work in progress no que se refere aquele. Quiçá, se a hermenêutica fosse o caso (ou o tema), então se diria haver uma circularidade hermenêutica entre a pré-compreensão dos ensaios e a fusão de horizontes históricos no "projeto" (em sentido heideggeriano) do pesquisador.

No que concerne ao Método de Procedimento, este artigo apoia-se em etapas bem definidas. Isto é, utiliza o Método Analítico conjugado ao Método Histórico, visto que as análises serão posicionadas na perspectiva de sua fundação histórico-conceitual (jurídica, filosófica e sociológica). Por fim, a técnica de pesquisa manejada foi a de levantamento bibliográfico, recolhendo-se fontes doutrinárias suficientes para a fundamentação da investigação. 


\subsection{Episteme}

O prestigiado filósofo francês Jacques Derrida, no penúltimo ensaio da coletânea "A Escritura e a Diferença" (2009), denominado "A Estrutura, o Signo e o Jogo no Discurso das Ciências Humanas",2, principia a análise lançando a hipótese de que houve um "acontecimento" na história do conceito de "estrutura". Tal acontecimento, segundo Derrida, "teria a forma de uma ruptura e de um redobramento" (2009). Ora, a problemática derridaiana é marcada pela desconstrução das estruturas nas variadas formas em que aparecem. Por essa razão, o filósofo é considerado um dos expoentes da teoria "Pós-estruturalista". Interessante aos nossos propósitos, aqui, é o percurso de sua argumentação.

Derrida observa que o conceito e a palavra "estrutura" são contemporâneos historicamente à "episteme" (Ciência e Filosofia Ocidental). Dessa forma, a apreensão da "estruturalidade" da estrutura, embora sempre tenha estado em movimento, foi "neutralizada" ou "reduzida" pelo gesto filosófico-científico que repetidamente deu-lhe um "centro", um "ponto de presença", uma "origem fixa" (DERRIDA, 2009). O centro tem papel de organização da estrutura, ao passo que esta característica lhe é essencial. Assim, o centro organizador da estrutura limita o que Derrida denomina de "jogo da estrutura". Não obstante, também possibilite "o jogo dos elementos no interior da forma total", haja vista que o centro lhe confere orientação, bem como organiza a coerência do sistema. (DERRIDA, 2009, p. 407)

Derrida detalha que o centro abre e torna possível o jogo, mas também é responsável por encerrá-lo. O centro enquanto centro apresenta, pois, um aspecto fundamental: nele, não há possibilidade de "substituição dos conteúdos, dos elementos, dos termos". No centro, portanto, a permuta ou transformação dos elementos permaneceu "interditada" (DERRIDA, 2009, p. 408). Consequentemente, sempre se concebeu o centro da estrutura como único, como "aquilo que comandando a estrutura, escapa à estruturalidade" (DERRIDA, 2009, p. 408). Nesse ponto, este interlúdio epistêmico deita raízes pari passu às pretensões pragmático-sistêmicas da investigação. Isto é, Derrida comenta que o "pensamento clássico da estrutura" concebe o centro, paradoxalmente, na estrutura e também fora da estrutura. Em suas palavras: "Está no centro da totalidade e, contudo, dado que o centro não lhe pertence, a totalidade tem o seu centro noutro lugar. O centro não é o centro.” (DERRIDA, 2009, p. 408).

\footnotetext{
${ }^{2} \mathrm{O}$ escrito, originalmente, foi uma conferência pronunciada no Colóquio Internacional da Universidade John Hopkins, Baltimore, sobre “As Linguagens Críticas e as Ciências Humanas”, em 21 de outubro de 1966.
} 
Derrida colhe outras consequências de seu raciocínio sobre as "estruturas centradas". Isto é, “[...] embora represente a própria coerência, a condição da episteme como fillosofia ou como ciência - é contraditoriamente coerente" (DERRIDA, 2009, p. 408). Na história da metafísica ocidental, o centro recebeu indiferentemente as designações de "origem ou de fim", de "arquê ou de télos" (DERRIDA, 2009). Portanto, o centro recebeu repetidamente formas ou nomes diferentes, pois a história da metafísica ocidental "seria a história dessas metáforas e dessas metonímias". Sendo assim, os "nomes do centro, do fundamento ou do princípio indicaram sempre o invariante de uma presença (eidos, arque, télos, energeia, ousia, aletheia, transcendentalidade, consciência, Deus, homem etc.)" (DERRIDA, 2009, p. 409).

A ruptura aludida ao começo por Derrida verificou-se quando passou a ser pensada e questionada a estruturalidade da estrutura. Indagação que paira sobre:

[...] a lei que comandava de algum modo o desejo do centro na constituição da estrutura, e o processo da significação ordenando os seus deslocamentos e as suas substituições a essa lei da presença central; mas de uma presença central que nunca foi ela própria, que sempre já foi deportada para fora de si no seu substituto. O substituto não substitui a nada que lhe tenha de certo modo preexistido. Desde então, deve-se sem dúvida ter começado a pensar que não havia centro, que o centro não podia ser pensado na forma de um sendo-presente, que o centro não tinha lugar natural, que não era um lugar fixo, mas uma função, uma espécie de não-lugar no qual se faziam indefinidamente substituições de signos. Foi então o momento em que a linguagem invadiu o campo problemático universal; foi então o momento em que, na ausência de centro ou de origem, tudo se torna discurso - com a condição de nos entendermos sobre esta palavra -, isto é, sistema no qual o significado central, originário ou transcendental nunca está absolutamente presente fora de um sistema de diferenças. A ausência de significado transcendental amplia indefinidamente o campo e o jogo da significação. (DERRIDA, 2009, p. 409-410).

O texto de Derrida é insinuante e lança-nos luz sobre o tema a ser investigado nas linhas abaixo. Qual seja: o pensamento das estruturas centradas na presença revelou-se paradoxal, contraditório, na medida em que o centro está dentro e fora da estrutura. Talvez, esse contexto indique a emergência das teorias que não "fujam" ou tentem evitar os paradoxos, ao passo que figuram como questões incontornáveis. A ressignificação do paradoxo, portanto, será um leitmotiv da Matriz Pragmático-Sistêmica, que argumentará em defesa da "circularidade" autorreprodutiva das operações comunicativas. 
Além disso, ela descortina-se como uma racionalidade que não designa como fixo o "centro das estruturas", promovendo, desse modo, um descentramento. Ora, a partir da metafísica moderna a substância das coisas passa a ser a subjetividade transcendental (Kant), o que significa o sujeito como estrutura centrada. Por outro lado, a racionalidade pragmáticosistêmica articula o sentido desconectado de estruturas centradas na "presença". Portanto, exteriorizando o abandono de um lugar fixo em prol de uma dinâmica funcional.

A epistemologia social construtivista, que instrui o paradigma pragmático-sistêmico, não deixou de recepcionar a invasão do mundo pela linguagem ocorrida no século XX. O que ampliou, assim, o campo e o jogo da significação. Não à toa o professor Teubner projeta como identidade entre as teorias pós-estruturalistas e pragmático-sistêmicas, o óbice em descrever a complexidade social por meio da linguagem ordinária (2005a). Complexidade social que também pode ser vislumbrada como um "sistema de diferenças", na feliz expressão de Jacques Derrida. Nesse cenário, é oportuno relançar a pergunta pela episteme no Direito: enfim, procede ou não a hipótese do descentramento epistemo-lógico do sujeito na validação do conhecimento jurídico?

\section{AUTOPOIESE COMO CONDIÇÃO DO CONHECIMENTO SISTÊMICO}

A resposta à questão da função da autopoiesis na justificação do conhecimento jurídico relaciona-se à reconstrução de alguns conceitos da teoria dos sistemas sociais autopoiéticos (LUHMANN, 2002; 2016) ${ }^{3}$. O ponto de partida é que a sociedade constitui-se como um sistema e que o sistema social é estabelecido pela comunicação. Portanto, permitindo o exame dos fenômenos sociais por meio das dinâmicas comunicativas que lhes vinculam e lhes organizam como totalidade (ROCHA, 2013b). Em vista disso, Clam observa que a autopoiese pode "ser definida simplesmente como a qualidade de um sistema 'que organiza a conectabilidade' (por intermédio de seus elementos)" (CLAM, 2013, p. 90). Ademais, verifica-se no mundo concreto que os vínculos sociais são diferentes, que são

\footnotetext{
${ }^{3}$ O professor e tradutor lusitano de G. Teubner, José Engrácia Antunes, em prefácio à obra "O Direito como Sistema Autopoiético", pontuou com clareza a transposição que Luhmann empreendeu da autopoiese dos sistemas vivos à autopoiese dos sistemas sociais. Dado o contexto argumentativo deste escrito, é pertinente observarmos as palavras do professor português: "[...] para LUHMANN, auto-referência e circularidade constituem o 'princípio vital' (Gestalt Prinzip), não apenas de células, sistemas nervosos, ou organismos biológicos vegetais ou animais em geral, mas igualmente dos próprios sistemas sociais. Deste modo, a autopoiesis deixa de ser concebida simplesmente como a condição necessária e suficiente da vida para assumir o estatuto de modelo explicativo de base de todo e qualquer sistema, desde os sistemas biológicos e os sistemas psíquicos até aos próprios sistemas sociais.” (ANTUNES, 1989, p. X).
} 
únicos; explicando, talvez, porque a teoria luhmanniana não saliente a racionalidade, o consenso ou a identidade. Em contrapartida, Luhmann matiza "a produção da diferença, da fragmentação, da singularidade" (ROCHA, 2013b, p. 29).

Segundo Luhmann (2002), a sociedade moderna caracteriza-se pela diferenciação funcional dos (sub)sistemas ("sistemas sociais parciais"), ou seja, há uma fragmentação e especialização de funções pelos subsistemas do sistema social. Desse modo, o sistema do direito constitui o código do direito, o sistema econômico constitui o código da economia, e assim sucessivamente com os demais sistemas sociais parciais (ALCOVER, 1993). Uma importante consequência da dinâmica da diferenciação é constatada na construção de sentido pelos sistemas, ao passo que "somente os sistemas são dotados de sentido, sendo que o ambiente é apenas uma complexidade bruta, que ao ser reduzido, já faz parte de um sistema" (ROCHA, 2013b, p. 35). King também argumenta nessa direção: “[...] definindo os sistemas sociais não como grupos de pessoas [...], mas como sistemas de significado.” (KING, 2009, p. 78).

Portanto, as noções de sentido e de comunicação estão no núcleo dos sistemas sociais autopoiéticos, pois para Luhmann "somente a comunicação pode produzir comunicação. A comunicação, assim, articula-se com a discussão a respeito dos chamados 'Meios de Comunicação Simbolicamente Generalizados"." (ROCHA, 2013b, p. 35). O professor Leonel S. Rocha reproduz a noção de "comunicação" em Luhmann como a síntese entre: “[...] informação, o ato de comunicação e a compreensão.” (ROCHA, 2013b, p. 35). Esta síntese é possível dependendo da forma como os meios de comunicação permitem a produção do sentido. Nesse contexto, a comunicação como o cerne dos sistemas sociais autopoiéticos assinala algo no que se refere ao descentramento epistemo-lógico do sujeito. O caso é que a condição de sentido no sistema autopoiético do Direito não se origina na racionalidade lógica - como condição de representação dos objetos jurídicos. Nesse contexto, Schwartz afirma que:

Disso tudo, resulta uma disposição evolutiva palpável, que faz com que a comunicação limite a complexidade indeterminável e não manipulável da sociedade, pré-configurando o campo das possibilidades que nela podem ser realizados. Com isso, quer-se dizer que a comunicação precede aos sujeitos, tornando-se seleção de sentido que estabelece seu próprio limite. [...]. Também se pode dizer que o sentido é, em verdade, o meio pelo qual o sistema traz para si a complexidade do seu entorno. O horizonte de 
possibilidades dado pelos sistemas reside na unidade de sua diferença com o entorno. Ao contrário de Weber, o sentido na teoria dos sistemas não é derivado de uma representação intencional na mente dos indivíduos. $\mathrm{O}$ sentido não é consequência da ação, mas sim da distinção sistema / entorno. (SCHWARTZ, 2013, p. 63-64).

A distinção entre sistema e entorno ou ambiente é capital na explicação da autopoiese dos sistemas sociais como condição do sentido. Antunes salienta que a autopoiese não significa apenas a auto-organização, mas, principalmente, a autorreprodução de seus elementos (ANTUNES, 1989). Segundo o professor português, esses sistemas autorreprodutores são: “[...] capazes de produzir esses próprios elementos, de produzir as suas próprias condições originárias de produção, tornando-se desse modo independentes do respectivo meio envolvente." (ANTUNES, 1989, p. XI). A faceta autorreprodutora da autopoiese dos sistemas sociais, dessa forma, desvela um importante papel prático e teórico que a categoria articula.

Antunes acentua a comunicação oriunda dos sistemas sociais como a gênese da intersubjetividade no sistema social. Além disso, ressalta como essa intersubjetividade não se dá via racionalidade de sujeitos cognitivos isolados (solipsistas). Destarte, o jurista realça com maestria o ponto:

Com efeito, no domínio dos fenômenos sociais, a unidade básica de análise é ainda o 'acto comunicativo', isto é, toda a interacção simbolicamente cristalizada que, ainda que de forma não voluntária, sucede a gerar e desenvolver um determinado padrão intersubjetivo de conduta. Logo que um tal padrão de conduta passe a orientar prospectivamente as relações intersubjectivas (ou seja, o padrão das interacções passadas passe a operar como pressuposto e limite das interacções futuras), assistimos à emergência de um sistema comunicativo. Ora é nisso justamente que consiste o sistema social: um sistema autopoiético de comunicação, ou seja, um sistema caracterizado por um perpetuum mobile auto-reprodutivo e circular de actos de comunicação que geram novos actos de comunicação. [...]. Isto traduz também claramente a autonomia do social e do biológico, já que o indivíduo participa no sistema social mas não faz parte deste: ou seja, se é certo que é através dos indivíduos que tal padrão do discurso comunicativo existe, certo é também que tal padrão, uma vez fixado, passa a constituir um pressuposto metacomunicativo da própria comunicação, como tal exterior e não manipulável pelos participantes (que podem, quando muito, tematizar tal padrão, mas não alterá-lo, sob pena de abandonarem o pressuposto do próprio discurso comunicativo, colocando-se de fora do sistema de comunicação. (ANTUNES, 1989, p. XII). 
O professor da Universidade de Reading (UK), Michael King, em artigo intitulado “A verdade sobre a autopoiese no direito" (2009), apresentou uma percuciente síntese de algumas críticas à teoria do Direito como sistema autopoiético, oriundas de estudiosos angloamericanos. Obviamente, não há como reconstruí-las por completo, pois excederia o escopo deste escrito; remetemos o leitor interessado, assim, ao texto do professor King. Entretanto, é válido destacar um ponto da crítica de Arthur Jacobson, no artigo "Autopoietic Law: The New Science of Niklas Luhmann", publicado na "Michigan Law Review" (87 [1989], p. 1647 1689), também analisado pelo professor inglês (KING, 2009, p. 56 e ss).

À luz da crítica à concepção luhmanniana da "unidade do sistema legal", Jacobson acusa Luhmann de ter tratado o sistema do direito como "supraindividual". Em outras palavras: o indivíduo real ficaria expurgado da autopoiese jurídica. Esse aspecto implicaria, segundo Jacobson, na "marginalização do indivíduo" e, por conseguinte, na aproximação da teoria autopoiética do direito dos "positivismos e dos naturalismos". No entanto, a recusa em utilizar o indivíduo como unidade de análise (Luhmann) deve necessariamente ser reparada perante dois critérios (que estamos demonstrando como verdadeiros nesta exposição): a) um sistema jurídico de fato autopoiético deve incluir o indivíduo nas operações de autorreprodução do sistema; e b) o descentramento do indivíduo no sistema jurídico visa justamente não cair na necessidade de uma das versões da "lei como revelação" (LUHMANN apud KING, 2009, p. 62). Portanto, a análise de Jacobson não é fiel ao que Luhmann propriamente sustentou. Em suma, assiste razão ao professor King quando declara que há considerável distorção entre a concepção de autopoiese em Luhmann e aquilo que referiu como o "voo imaginário" de Jacobson (KING, 2009).

Os "sistemas diferenciados" apresentam como condição da manutenção de sua unidade ser "operativamente fechados" e, ao mesmo tempo, "cognitivamente abertos" (KING, 2009), visando contemplar a diferença que lhes constitui. Esta simultaneidade entre abertura e fechamento revela o paradoxo no interior dos sistemas; o que no caso do sistema do Direito resulta como "critério" para a tomada de decisões (TEUBNER, 1989; ALCOVER, 1993; ROCHA, 2013b). Teubner acentua que o que se mostra paradoxal é a realidade do direito e não apenas a reflexão sobre ele. Portanto, sobrevém "a transferência do paradoxo do mundo do pensamento sobre o direito para o mundo da realidade social do direito." (TEUBNER, 1989, p. 18) 
A noção de autopoiese aparece como alternativa à linearidade dogmática das teorias do direito com perspectiva "unidimensional" (ROCHA; MARTINI, 2016), que são inspiradas na lógica clássica da não-contradição. ${ }^{4}$ Nesse mesmo horizonte, Clam destaca que o "design teórico" luhmanniano pode ser prospectado como "topológico", no sentido que a matemática moderna empresta ao termo (CLAM, 2013). Dessa forma, as reflexões do sociólogo alemão estão articuladas a partir de “'lugares' primordiais, tais como a complexidade, o sistema e seu ambiente, a dupla contingência, o sentido, o 'fazer experimentar' (Erleben) e o agir, a comunicação, o tempo, a autorreferência" (CLAM, 2013, p. 81).

Teubner (1989) enfatiza que a teoria da autopoiese promove uma ruptura com o "tabu da circularidade". Esta ruptura, no entanto, não deve ser entendida como uma "aceitação pura de argumentos circulares", mas como uma "nova perspectiva da própria circularidade: esta deixaria de ser vista como um problema intelectual (relativo a erro de pensamento) para passar a ser interpretada como um problema relativo à própria práxis jurídica." (TEUBNER, 1989, p. 19). Portanto, Teubner refere-se a estes desdobramentos e notas conceituais da autopoiese dos sistemas sociais, enquanto ferramentas necessárias para investigar a práxis jurídica ("legislativa e jurisprudencial") (TEUBNER, 1989). Ou seja, como ela lida com os paradoxos da autorreferência e como obtém certa estabilidade, a despeito de apresentar oscilações? Teubner afirma que:

A absoluta indeterminação do direito transforma-se então numa
indeterminação relativa. A teoria da autopoiesis oferece uma análise das
soluções da prática jurídica para o problema da indeterminação do direito
graças à conjugação dos seguintes elementos: auto-referência, paradoxo,
indeterminação, estabilidade através de valores próprios. Através da
aplicação da sua própria distinção entre legal/ ilegal, o sistema jurídico
constrói a si mesmo na base de um círculo auto-referencial. Semelhante
auto-referencialidade conduz inevitavelmente a situações tautológicas e
paradoxais, sendo assim, por conseguinte, responsável por uma relativa
indeterminação do próprio direito. Isto não significa, no entanto, que

${ }^{4}$ Uma das lições que se herda de Aristotéles e da lógica clássica é em relação ao par conceitual contingência/necessidade. Com efeito, a relação de necessidade é analítica ou puramente lógica ("necessitarismo lógico"), ou seja, a verdade do seu enunciado não depende de qualquer atestado empírico (ex.: "Cinco mais cinco é necessariamente dez"); por oposição, o contingente é tudo aquilo que pode ser de modo diverso ao do que é (ex.: "O jogo acabou"). Note-se que a contingência está atrelada indissociavelmente aos eventos do mundo histórico-concreto ou social. Especialmente por isso, será um importante aspecto nas observações da matriz pragmático-sistêmica. Nesse contexto, as respostas teóricas aos problemas do sistema social inspiradas no "necessitarismo lógico" cedem passo, pois não conseguem dar conta dos dilemas da sociedade fragmentada em múltiplas diferenças. Vale dizer que, neste local-de-fala pragmático-sistêmico, essa dissolução provoca o risco constante da frustração de expectativas que a contingência suscita. 
tenhamos que render-nos fatalisticamente a tal resultado, uma vez que existem soluções para os problemas de indeterminação originados pelo paradoxo (TEUBNER, 1989, p. 24).

Em suma, a autopoiese como condição da construção de sentido do sistema do Direito vincula-se à validade do conhecimento jurídico (ALCOVER, 1993). Isto é, a autonomia plena da "legitimidade jurídica" deve ser conferida ao "sistema jurídico em si mesmo, tornando-se o único símbolo de sua unidade." (CLAM, 2013, p. 105). É neste horizonte que a matriz pragmático-sistêmica aproxima-se da nossa hipótese. Isto é, o sujeito lógico do conhecimento como condição do sentido, típico das descrições verdadeiras ou falsas da ciência jurídica clássica, perde centralidade como ponto de partida epistêmico. Com efeito, a racionalidade pragmático-sistêmica no Direito oferece um novo começo epistêmico a partir da autopoiese. Além disso, "trata-se de uma observação da complexidade, e não um retorno naif ao descritivismo da dogmática" (ROCHA, 2009, p. 11). Portanto, configura-se teoreticamente como a observação dos "fenômenos que se desdobram como resultado das operações contingentes na comunicação dos sistemas sociais.” (KING, 2009, p. 73).

Resta-nos, porém, a análise do último aspecto de nossas pegadas autopoiéticas, cujo caminho percorrido até aqui parece confirmar a hipótese assumida ao início. Tal como afirmamos antes, a espécie de logos conceitual deste escrito foram as ideias do professor Teubner presentes à coletânea intitulada "El Derecho como Sistema Autopoiético de la Sociedad Global” (2005a), precisamente, no capítulo inicial: "El Derecho como Sistema Autopoiético".

$\mathrm{Na}$ trilha da "boa circularidade" de nosso "sistema psíquico", partimos dos pressupostos pragmático-sistêmicos que embasaram a mencionada reflexão do professor Teubner, para então aportarmos nas questões cruciais que nos serviram de gatilho intelectual. Desse modo, elevam-se as interrogações finais: por que os argumentos do capítulo mencionado ensejaram a intuição intelectual do descentramento do sujeito na validação do conhecimento jurídico? O que significa a sugestão do professor Teubner do sistema do direito configurar-se como o novo sujeito epistêmico? Nossa seção final estruturar-se-á no horizonte dessas indagações.

\section{CONSTRUTIVISMO: O SISTEMA DO DIREITO COMO SUJEITO EPISTÊMICO}


Nesta seção, comentaremos o texto "El Derecho como Sistema Autopoiético" (TEUBNER, 2005a) ${ }^{5}$, explicitando a autopoiese do sistema jurídico como ferramenta cognitiva do Direito (análise com unidade focal circunscrita ao anti-individualismo e ao antirrealismo epistêmicos, fundamentos de nossa hipótese). O professor Teubner nota a fragmentação da linguagem teórica da sociologia do direito, que decorre do retorno das "grandes teorias nas ciências humanas" (Q. Skinner). Essa fragmentação implicou na divisão da sociologia do direito em "diversas províncias conceituais". O que resultou em certa obscuridade na linguagem utilizada à representação dos fenômenos sociológico-jurídicos, isto é, o "Galimatazo (Jabbervocky)" - no jogo de linguagem utilizado por Teubner para colorir esta instância de obscuridade da linguagem jurídico-teórica. (TEUBNER, 2005a)

As teorias pretendem abarcar realidades sociojurídicas complexas. Um problema que aponta para a impossibilidade de descrição através da linguagem ordinária. Precisamente, devido à insuficiência discursiva frente à referida complexidade. Esse aspecto é compartilhado pelas teorias do direito com inspiração no pós-estruturalismo, na teoria crítica e na teoria da autopoiese. Desse modo, Foucault, Habermas e Luhmann, acrescenta Teubner, “imaginan unas realidades sociales cuya construcción va más allá de los limites del linguaje ordinario.” (TEUBNER, 2005a, p. 23; BERGER; LUCKMANN, 1995). As reflexões dos autores estão apartadas da denominada "reificação da 'metafisica quotidiana' (Pizzorno)", cujas características são o realismo epistemológico e o individualismo metodológico. (TEUBNER, 2005a; BERGER; LUCKMANN, 1995)

Portanto, apesar das diferenças entre as teorias jurídicas do pós-estruturalismo (discurso), da teoria crítica (autorreflexão social) e da teoria da autopoiese (auto-organização), elas comungam de dois atributos epistêmicos primordiais: o antirrealismo e o antiindividualismo (TEUBNER, 2005a). No que se refere ao Direito, à conjugação da mudança epistemológica e da nova percepção da individualidade apontam que "[...] el constructivismo se deshace de la ingenua suposición realista de que los actores humanos, a través de sus

\footnotetext{
5 Originalmente publicado na "Law \& Society Review 23 (1989), pp. 727-757, sob o título: "How the Law Thinks: Toward a Construtivist Epistemology of Law". Posteriormente, incorporando reflexões do artigo: "Die Episteme des Rechts. Zu erkenntnistheoretischen Grundlagen des reflexiven Rechts", publicado em: GRIMM, Dieter (ed.), Wachsende Staatsaufgaben - sinkende Steuerungsfahigkeit des Rechts. Baden-Baden: Nomos, 1990, pp. 115-155. A versão utilizada é a editada por Carlos Gómez-Jara Díez, de 2005 (ARA Editores), em espanhol. As passagens que porventura aparecerem traduzidas será de nossa responsabilidade. Não obstante, sempre que a citação traduzida ocorrer de modo direto haverá a indicação da página para que o leitor possa orientar possível consulta.
} 
acciones intencionales, configuran los elementos básicos de la sociedad.” (TEUBNER, 2005a, p. 24).

A epistemologia social construtivista não oferece uma ideia de realidade subordinada a de realidade social como algo que está "fora", ou seja, que pressuponha algum tipo de dualismo em sua constituição (BERGER; LUCKMANN, 1995). De outra banda, “[...] es el Derecho el que, como sujeto epistémico autónomo, construye su propia realidade social." (TEUBNER, 2005a, p. 24). E esta construção da realidade traz à tona o descentramento epistemo-lógico do sujeito, visto que o sujeito transcendental deixa de ser à base de representação da realidade, assim como nas teorias do direito de inspiração clássica. $\mathrm{O}$ que leva Teubner a sustentar que o Direito não é produto das ações intencionais dos seres humanos. Na verdade, "es el Derecho como um artefacto cultural". Ademais, concluindo que: "Muy al contrario, es el Derecho el que, como processo comunicativo, crea actores humanos como artefactos semânticos a través de sus operaciones jurídicas.” (TEUBNER, 2005a, p. 25).

Portanto, a teoria da autopoiese propicia uma nova cognição social que the afugenta do "individualismo metodológico". Com efeito, a ideia de que "todo fenômeno coletivo seja reduzido às ações intencionais dos indivíduos" não se verifica na racionalidade pragmáticosistêmica (TEUBNER, 2005a). Estrutura-se, assim, como uma oportuna via de escape ao pensamento hegemônico, notadamente de corte realista e individualista. A teoria da autopoiese, a teoria crítica e o pós-estruturalismo, consequentemente, "reemplazan al individuo autónomo por procesos comunicativos y no por entidades supra-individuales." (TEUBNER, 2005a, p. 28-29). É importante notar, também, que Luhmann e Foucault foram mais radicais no "desencantamento com o sujeito individual". No que que se refere à teoria da autopoiese, Teubner pondera que:

LUHMANN separa totalmente los procesos psíquicos de los sociales y percebe al individuo en la sociedad como un artefacto semântico, como un producto de la auto-observación de la autopoiesis social. Los nuevos sujetos epistémicos son los sistemas sociales autopoiéticos. (TEUBNER, 2005a, p. 29).

A teoria do direito que pretenda estruturar-se como uma epistemologia jurídica deve reformular o modo como são concebidos o Direito e a sociedade (ALCOVER, 1993). Essa operação pode ser vislumbrada a partir de três mudanças essenciais: I) na substituição do realismo pelo construtivismo; II) na troca da construção individual da realidade pela 
construção social da realidade (TEUBNER, 2005a; BERGER; LUCKMANN, 1995); e III) ao alterar a concepção de Direito como sistema de normas para a de Direito como sujeito epistêmico (TEUBNER, 2005a).

O primeiro item implica o abandono da epistemologia kantiana (KANT, 2001), enquanto que os outros dois "abren un nuevo camino en la teoría jurídica y social" (TEUBNER, 2005a, p. 29). A operação conceitual da construção social da realidade explicita os fundamentos sociais da cognição como nenhuma outra sociologia tradicional do conhecimento conseguiu (BERGER; LUCKMANN, 1995). Com relação ao terceiro item: "atribuye la creación de una realidad social autónoma a las prácticas discursivas del Derecho." (TEUBNER, 2005a, p. 29).

O professor Teubner reparou um aspecto antes destacado, que pela importância teórica merece o realce: o uso produtivo dos paradoxos da autorreferencialidade (ROCHA; MARTINI, 2016). Portanto, enquanto sistemas autopoiéticos, a justificação dos discursos está atrelada indissociavelmente a sua própria circularidade; além disso, “[...] não podem senão produzir regularidades que se regulam a si próprias e que governam a transformação de suas próprias regularidades.” (TEUBNER, 2005a, p. 36).

Portanto, os paradoxos da autorreferência não são um erro lógico do pensamento, mas uma realidade que não se pode estar livre de forma nenhuma. Ou seja, "os discursos sociais aprendem de modo 'cego' aqueles modos operacionais que resultam válidos para adaptar-se a um entorno ao qual não tem acesso." (TEUBNER, 2005a, p. 37). O construtivismo radical, dessa forma, aparece como consequência do processo cognitivo da realidade (BERGER; LUCKMANN, 1995). Teubner destaca que qualquer conhecimento é construído internamente pelo mundo exterior, pois o conhecimento não tem acesso a uma realidade "aí fora", como pontuado acima. Os processos cognitivos, sejam teóricos ou empíricos, constituem-se como uma construção interna da unidade cognoscente. O exame de validade das construções internas, na relação com a realidade externa, trata-se apenas de uma comparação interna de diferentes construções do mundo (TEUBNER, 2005a; BERGER; LUCKMANN, 1995).

O autor alemão pontua que esta versão radicalizada da "construção social da realidade" exclui a "acción o el pensamiento individual" (TEUBNER, 2005a, 37), rememorando o fundamento do presente artigo. A autopoiese social estrutura-se unicamente a 
partir da comunicação; a qual se constitui, tal como antes delineado, por meio da síntese de "participação, informação e compreensão - que recursivamente reproduz a comunicação" (TEUBNER, 2005a, 38). Dessa forma, há uma separação entre a construção social da realidade e a construção psíquica da realidade. Teubner lembra-nos que:

Para a teoria da autopoiesis, os processos psíquicos formam sua própria rede reprodutiva fechada - autopoiesis psíquica -. Esta só é acessível a eles mesmos e se mostra totalmente inacessível à comunicação. Por seu lado, a comunicação forma uma rede autorreprodutiva própria - autopoiesis social acessível apenas à comunicação e inacessível a qualquer processo psíquico. Certo é que os indivíduos reaparecem no mundo da comunicação, mas só como construções comunicativas, como artefatos semânticos sem correspondência com a consciência ou com os processos autopoiéticos do mundo psíquico (TEUBNER, 2005a, p. 38).

Assim, há uma coexistência entre os processos psíquicos e sociais. Eles encontram-se acoplados através da sincronização e da coevolução, porém, com autonomia nas respectivas dinâmicas operacionais. Há uma simetria na construção da realidade: "los procesos psíquicos producen constructos mentales de la sociedad, y los procesos sociales producen constructos comunicativos de la psique." (TEUBNER, 2005a, 38). Portanto, o descentramento do sujeito lógico como fonte absoluta do sentido tem assento na interpretação do professor Teubner. Aliás, segundo ele, "a radicalização do construtivismo e a desindividualização do discurso" elevam-se como um desenvolvimento de conteúdo da epistemologia social, sobretudo em relação às variantes habermasiana e foucaultiana (TEUBNER, 2005a).

Luhmann ofereceu uma ideia da modernidade como a disputa permanente entre diferentes epistemes. Isto é, a fragmentação da sociedade numa multiplicidade de discursos autônomos apresenta uma diversificação de epistemes. Isso significa que a perda de um modo unitário de cognição (tal como fora "Deus" no medievo) exsurge como a propriedade fundamental do mundo moderno. A fragmentação social dá-se na forma de múltiplas "redes comunicativas fechadas", em que cada rede é responsável pela construção de sua realidade própria; construções que, em princípio, resultam incompatíveis entre si (TEUBNER, 2005a).

Ao mesmo tempo, a multiplicação e fragmentação de individualidades correspondem à multiplicação e fragmentação dos discursos sociais. Sobre a base de seus códigos e programas específicos, cada rede de comunicação especializada produz 'pessoas' - artefatos semânticos de atores individuais - 
aos quais atribui ações. O 'Ser-Múltiplo' (Elster) é o produto da fragmentação de discursos sociais na modernidade (TEUBNER, 2005a, 39).

O anti-individualismo ou supressão do sujeito lógico como base do conhecimento jurídico molda o conhecimento individual, conforme a socialização por instituições sociais, assim como o Direito. Afinal,

[...] instituciones tales como el Derecho "conocen" independientemente de las mentes de sus miembros. El Derecho procesa autónomamente información, crea mundos de sentido, fija objetivos y fines, produce construcciones de la realidad y define las expectativas normativas - y todo esto independientemente de las construcciones del mundo que existen en las mentes de los juristas (TEUBNER, 2005a, p. 41).

Destarte, o Direito constitui-se como um sistema social autopoiético, o que indica "uma rede de operações elementares que recursivamente reproduz operações elementares. Os elementos básicos deste sistema são comunicações, não normas” (TEUBNER, 2005a, p. 42). Sendo assim, as teorias do direito "analítico-normativistas" e "sociológico-realistas" falharam na identificação da propriedade fundamental do sistema do Direito. As primeiras, ao conceberem o Direito como sistema de normas; já as sociológico-realistas, ao concebê-lo como sistema de profissionais e organização jurídica, portanto, pressupondo o ser humano como elemento epistêmico (TEUBNER, 2005a).

O sistema autopoiético do Direito, tal como vimos, caracteriza-se pela autoorganização e autorreprodução de seus elementos. A compreensão da condição autorreprodutiva vincula-se às comunicações como propriedades fundamentais do sistema do Direito (ALCOVER, 1993). Elas são os "instrumentos cognitivos" através do qual o discurso social do Direito tem a possibilidade de "ver o mundo". Teubner disserta que:

El mundo exterior no instruye en modo alguno al Derecho; sólo existe una construcción del mundo exterior por parte del Derecho. Esto no quiere decir que el Derecho "inventa" arbitrariamente la realidad social. Una perspectiva constructivista no debe ser confundida con el "solipsismo metodológico"; más bien busca un camino intermedio entre el representacionalismo y el solipsismo. El constructivismo jurídico presupone entonces la "existencia" de un entorno para el Derecho. La cuestión no es un aislamiento monadológico del Derecho, sino la construcción autónoma de modelos jurídicos de realidad bajo la impresión de las perturbaciones ambientales. ¡Orden jurídico a partir del ruido social! (TEUBNER, 2005a, p. 43). 
Portanto, o sistema do direito como novo sujeito epistêmico sinaliza que as pessoas com as quais ele lida não são as pessoas de carne e osso, dotadas de mente e cérebro. Consequentemente, não são os sistemas psíquicos autopoiéticos (TEUBNER, 2005a). Todavia, são meros constructos, artefatos semânticos fabricados pelo discurso do Direito. E no que se refere ao "ambiente" psíquico, vale dizer que são: [...] en realidad [sic!] constructos de los discursos prácticos, necesarios para la formación de círculos comunicativos, de comunidades discursivas" (TEUBNER, 2005a, p. 44-45). Isso não indica uma "deshumanização" da teoria do Direito, tampouco a supraindividualização epistêmica (Jacobson).

Como constructos sociales, las personas son indispensables para la comunicación jurídica, ya que el Derecho, como proceso social, necesita atribuir la comunicación a un actor (individual o colectivo) en aras de continuar su autorreproducción. Pero estos "actores" son únicamente un conjunto de roles (roles-bundels), máscaras de personajes (character-mask), productos internos de la comunicación jurídica (TEUBNER, 2005a, p. 4445).

É importante acentuar que, a substituição do sujeito individual deve compartilhar a atenção reflexiva, haja vista a centralidade temática da "multiplicação dos centros de cognição". O professor Teubner pondera que os "discursos sociales son los nuevos sujetos epistémicos que compiten con la conciencia del individuo" (TEUBNER, 2005a, p. 46). Então, os múltiplos centros de cognição parecem culminar na ideia de "policontexturalidade" (TEUBNER, 2005b). Ora, se a observação deixa de partir do sujeito individual, então ela deixa de ser "monocontextural" (TEUBNER, 2005b; 2005a; ROCHA, 2009). A teoria autopoiética sustenta a autonomia epistêmica de uma diversidade de discursos sociais e, assim, “[...] toma parte en la 'descentralización del sujeto', esto es, en alejar al sujeto de su posición privilegiada como centro del conocimiento único y último.” (TEUBNER, 2005a, p. 46).

A perspectiva construtivista confere ao sistema do Direito uma autoridade epistêmica que é intransponível. O construtivismo epistemológico refuta o velho dogma da ciência moderna de "autorrevelar-se" como o único conhecimento verdadeiro. Isto é, impugna a pretensão da ciência moderna de supostamente desfrutar de um acesso privilegiado à realidade (BERGER; LUCKMANN, 1995). Isto sinaliza que a ciência não descobre fatos exteriores, no entanto, os constrói. O construtivismo radical, segundo Luhmann, advoga que a 
ciência opera uma construção de mundo que está legitimada pelas próprias distinções e não pelo mundo como tal. (TEUBNER, 2005).

\section{CONSIDERAÇÕES FINAIS}

O fio condutor deste ensaio foi à hipótese do descentramento do sujeito na validação do conhecimento jurídico, segundo as reflexões pragmático-sistêmicas. Desse modo, demonstramos a Matriz Pragmático Sistêmica no Direito como a racionalidade apta a explicar, cognitivamente, as diversas demandas (jurídicas) da hodierna sociedade global. A complexidade social expressa na pluralidade de diferenças explicita o risco cotidiano frente às tomadas de decisão, na medida em que a contingência é a grande marca da sociedade fragmentada. O projeto antimetafísico de inspiração luhmanniana, portanto, operou a destranscendentalização do discurso jurídico, por meio da desindividualização do sujeito epistêmico. Até mesmo porque, pensar a produção da diferença ensejou a mudança no modo de produção da identidade, isto é, mobilizou o descentramento epistemo-lógico do sujeito.

Assim como detalhamos ao longo deste ensaio, o Direito como sistema autopoiético autorreproduz-se e auto-organiza-se. Em outras palavras, a autopoiesis do sistema jurídico faz com que o Direito construa os seus próprios componentes, a partir da dinâmica comunicativa que instaura entre eles. Isto é, o Direito produz as próprias condições originárias de produção (Teubner). Dessa forma, a noção de autopoiese é decisiva para se conceber o sistema do Direito como novo sujeito epistêmico, em detrimento das teorias de orientação individualista.

A autopoiese dos sistemas sociais como condição do sentido apontou para a comunicação como núcleo construtivo de suas operações. Sendo assim, o sentido revelou-se como o meio pelo qual o sistema avoca a complexidade do entorno ou ambiente. Em vista disso, a autonomia do sistema social estipula que o indivíduo participa do sistema social, contudo, não lhe faz parte. Embora seja através dos indivíduos que o padrão do discurso comunicativo existe, tal padrão, uma vez fixado, constitui um pressuposto metacomunicativo da própria comunicação (Antunes). Logo, veiculando-se como exterior e não manipulável pelos participantes. Afinal, os sistemas sociais autopoiéticos formam redes circulares e fechadas de operações sistêmicas. Portanto, a autorreprodução dos sistemas sociais é 
garantida pelo seu fechamento operacional (código próprio) associado a sua abertura cognitiva (ao entorno).

Conforme se delineou, a teoria da autopoiese organiza-se epistemologicamente como antirrealista e anti-individualista. É designada como uma epistemologia social construtivista, já que não oferece uma ideia de realidade atrelada à realidade social como algo que está fora do sujeito do conhecimento. Aliás, o Construtivismo externou o desencantamento com o sujeito individual, pois os sistemas sociais autopoiéticos despontam como os novos sujeitos epistêmicos, na medida em que constróem a própria realidade social.

O construtivismo epistemológico refuta o engodo da metafísica moderna de que apenas o conhecimento científico era válido. A tradição metafísica, sob o manto do necessitarismo lógico, escorregou na desconsideração de mundo que os cânones puramente formais implica(ra)m. A desconsideração do mundo histórico ou social ocorreu em nome do desprezo pela contingência, característica determinante do mundo concreto. A impossibilidade de se formalizar logicamente o contingente instigou o seu recalque epistemológico pelas teorias realistas e individualistas. Algo que não se verificou com a epistemologia social construtivista.

Finalmente, evidenciamos que o descentramento epistemo-lógico do sujeito liga-se à multiplicação dos centros de cognição. Portanto, os múltiplos centros de cognição parecem remeter à ideia de "policontexturalidade", pois, se a observação desprende-se do sujeito individual, então ela deixa de ser "monocontextural". Desse modo, novas perguntas devem ser colocadas a partir do diagnóstico do descentramento epistemo-lógico do sujeito no Direito, no horizonte de seu entrelaçamento com a policontexturalidade (TEUBNER, 2005b). Assim, as investigações devem avançar à análise da pressuposta conexão que une as ideias. Afinal, em que medida e de que modo à noção de policontexturalidade liga-se ao descentramento do sujeito na validação do conhecimento jurídico?

\section{BIBLIOGRAFIA}

ALCOVER, Pilar Giménez. "El Derecho em la Teoría de la Sociedad de Niklas Luhmann". Barcelona: J.M. Bosch Editor, 1993.

ANTUNES, José E. Prefácio. In: TEUBNER, Gunther. "O Direito como Sistema Autopoiético". Lisboa: Fundação Calouste Gulbenkian, 1989, pp. I - XXXII. 
BERGER, Peter L.; LUCKMANN, Thomas. "La Construcción Social de la Realidad". 13 reimp. Buenos Aires: Amorrortu Editores, 1995.

CLAM, Jean. A autopoiese no direito. In: CLAM, Jean; ROCHA, Leonel S.; SCHWARTZ, Germano. "Introdução à teoria do sistema autopoiético do direito". $2^{\mathrm{a}}$ ed., rev. e ampl. Porto Alegre: Livraria do Advogado Editora, 2013, pp. 77-128.

DERRIDA, Jacques. A Estrutura, o Signo e o Jogo no Discurso das Ciências Humanas. In: "A Escritura e a Diferença". 4a ed. São Paulo: Perspectiva, 2009, pp. 407-426.

KANT, Immanuel. “Crítica da Razão Pura”. 5ª ed. Lisboa: Fundação Calouste Gulbenkian.

KELSEN, Hans. “Teoria Pura do Direito". 4a ed. Coimbra: Arménio Amado Editor, 1976.

KING, Michael. A verdade sobre a autopoiese no direito. In: KING, Michael; ROCHA, Leonel S.; SCHWARTZ, Germano. "A verdade sobre a autopoiese no direito". Porto Alegre: Livraria do Advogado Editora, 2009, pp. 41-98.

LUHMANN, Niklas. "Introducción a la Teoría de Sistemas". Lecciones publicadas por Javier Torres Nafarrate. $1^{\text {a }}$ reimp. México: Universidad Iberoamericana, 2002.

LUHMANN, Niklas. "O Direito da Sociedade" [livro eletrônico]. São Paulo: Martins Fontes, 2016. ePUB

LUHMANN, Niklas. "Sociologia do Direito I". Rio de Janeiro: Edições Tempo Brasileiro, 1983.

ROCHA, Leonel S. "Epistemologia Jurídica e Democracia". 2a ed. São Leopoldo: Editora UNISINOS, 2003.

ROCHA, Leonel S. “A Problemática Jurídica: uma introdução transdisciplinar”. Porto Alegre: Sergio Antonio Fabris Editor, 1985.

ROCHA, Leonel S. Observações sobre a observação Luhmanniana. In: KING, Michael; ROCHA, Leonel S.; SCHWARTZ, Germano. "A verdade sobre a autopoiese no direito". Porto Alegre: Livraria do Advogado Editora, 2009, pp. 11-40.

ROCHA, Leonel S. Epistemologia do Direito: revisitando as três matrizes jurídicas. "Revista de Estudos Constitucionais, Hermenêutica e Teoria do Direito (RECHTD)", 5(2):141-149, julho-dezembro 2013a.

ROCHA, Leonel S. Da epistemologia jurídica normativista ao construtivismo sistêmico II. In: CLAM, Jean; ROCHA, Leonel S.; SCHWARTZ, Germano. "Introdução à teoria do sistema 
autopoiético do direito". $2^{\mathrm{a}}$ ed., rev. e ampl. Porto Alegre: Livraria do Advogado Editora, 2013b, pp. 45-76.

ROCHA, Leonel S.; MARTINI, Sandra Regina. "Teoria e Prática dos Sistemas Sociais e Direito". Porto Alegre: Livraria do Advogado Editora, 2016.

SCHWARTZ, Germano. A fase pré-autopoiética do sistemismo luhmanniano. autopoiese no direito. In: CLAM, Jean; ROCHA, Leonel S.; SCHWARTZ, Germano. "Introdução à teoria do sistema autopoiético do direito". $2^{\mathrm{a}}$ ed., rev. e ampl. Porto Alegre: Livraria do Advogado Editora, 2013, pp. 45-76.

TEUBNER, Gunther. "O Direito como Sistema Autopoiético”. Lisboa: Fundação Calouste Gulbenkian, 1989.

TEUBNER, Gunther. "El Derecho como Sistema Autopoiético de la Sociedad Global". Editor Carlos Gómez-Jara Díez. Lima: ARA Editores, 2005a.

TEUBNER, Gunther. "Direito, Sistema e Policontexturalidade". São Paulo: Editora da UNIMEP, 2005b.

TEUBNER, Gunther. "Fragmentos Constitucionais: constitucionalismo social na globalização”. São Paulo: Editora Saraiva, 2016. 